\title{
¿«La» 0 «Una» organización líder en migración? La OIM como un actor en la gobernanza migratoria mundial
}

\author{
«The» or «A» leading organization in migration? \\ IOM as an actor in global migration governance
}

Stefan Rother*

ISSN IMPRESO 1870-7599 | ISSN RED CÓMPUTO 2448-7783 | 137-159

RECIBIDO 12/03/20 | ACEPTADO 03/04/20

\begin{abstract}
Resumen. La emergente gobernanza mundial de la migración se caracteriza por su fragmentación en términos de instituciones, normativas y convenciones subyacentes. La Organización Internacional para las Migraciones (OIM) ocupa un lugar peculiar dentro de este marco: por un lado, hasta hace muy poco se había situado fuera de la Organización de las Naciones Unidas (ONU), se considera un organismo "no normativo" y ha actuado principalmente como un proveedor de servicios basado en beneficios para los Estados nacionales. Por otro lado, ha sido fundamental en el establecimiento de normativas influyentes como la "gestión migratoria»; asimismo, ha sido elogiada como «un organismo líder en migración» por la ONU y sus Estados miembro; finalmente, en septiembre de 2016, se adhirió a la ONU como una "organización conexa». Sin embargo, la oposición a la propuesta original de llamar a la OIM «el organismo líder en migración", destaca que más allá del aspecto semántico, el papel de la organización aún no se define con claridad y es discutible. Este aporte analiza la actuación que la OIM ha logrado en la gobernanza mundial de la migración.
\end{abstract}

Palabras clave: gobernanza mundial de la migración, desarrollo, OIM, actuación, organizaciones internacionales.

\begin{abstract}
The emerging global governance of migration is characterized by its fragmentation in terms of institutions, underlying norms and conventions. The International Organization for Migration (IOM) holds a peculiar place within this framework: On the one side, it has been situated outside the United Nations System until very recently, considers itself a "non-normative» agency, and has mostly acted as a profit-based service provider for nation-states. On the other side, the IOM has been instrumental in establishing influential norms such as «migration management», it has been lauded "a leading agency on migration" by the UN and its member states, and moved closer to the UN system as a «related organization» in September 2016. However, the opposition to the original suggestion of calling the IOM «the leading agency on migration» highlights - beyond mere semantics - that the role of the organization is still nor clearly defined and remains contested. This contribution analyses the actorness IOM has achieved in global migration governance.
\end{abstract}

Keywords: global migration governance, development, IOM, actorness, international organizations.

\footnotetext{
*Alemán. Adscrito al Instituto Arnold Bergstraesser de la Universidad de Friburgo, Alemania. Correo-e: mail@ stefan-rother.de

Traducido del inglés al español por Georgia Aralú González Pérez y Keilany Nohemy García Mendoza.
} 


\section{Introducción}

Cuando el segundo Diálogo de Alto Nivel de las Naciones Unidas (UN-HLD, por sus siglas en inglés) sobre la Migración Internacional y el Desarrollo, «Hacer que la migración funcione», tuvo lugar los días 3 y 4 de octubre de 2013 en Nueva York, los comentarios en la red social Twitter eran aún un fenómeno relativamente nuevo. Por ejemplo, mientras la Organización Internacional del Trabajo (OIT) estaba casi ausente en la red social, las oficinas de Nueva York y Ginebra de la Organización Internacional para las Migraciones (OIM) enviaban un tweet tras otro:

(William Lacy, Director General de la OIM) Swing: «Como organismo líder mundial en migración, la OIM antepone la protección de los \# migrants en todo lo que hace».

\#Chile at \#HLD2013: "La OIM ha desempeñado un papel importante como OIG y en la preparación para el Diálogo de Alto Nivel \#migration».

\#Austria: «Me gustaría agradecer a la \#OIM por su contribución al \#HLD2013». La OIM se encuentra en una posición única para enriquecer este debate en años venideros (todos los tweets de la OIM desde el 3 de octubre).

Nepal: «@IOM_news puede desempeñar un papel importante en mejorar el impacto positivo de los \# migrants».

Uruguay en el \#HLD2013: «El Plenario señala a la OIM como la organización líder mundial de migración».

«\#Egypt en el \#HLD2013 pide explorar formas para fortalecer la participación de la OIM dada su posición como organización líder OIG en el campo de la migración y se enorgullece de recibir en su oficina regional a \#MENA».

@UNAOC: «Trabajo importante con la@OIM_news en la creación de \#bestpractices for \#migration» (todos los tweets de la orm desde el 4 de octubre).

Estas citas - que son sólo una pequeña muestra de muchas otras en un tono similar y que representan la imagen pública proyectada por la OIM en los últimos años - pueden ser leídas de distintas maneras. En principio, concebimos una organización que espera reconocimiento y que acepta cualquier tipo de elogio. Después, es evidente que existe una base sólida para esta autopromoción, puesto que un número diverso de Estados, incluidos los países de origen y de destino, acudió para subrayar su trascendencia. A ellos se unió una iniciativa 
basada en la ONU, la Alianza de Civilizaciones de las Naciones Unidas (UNAOC, por sus siglas en inglés), y durante la sesión del 4 de octubre una importante organización regional también la enarboló a través de un representante, quien enfatizó que la Unión Europea (UE) «aprecia el liderazgo de la OIM en la migración y el desarrollo internacionales». Las aludidas declaraciones dan la impresión de que los participantes no la perciben como una simple herramienta que puede favorecer a sus objetivos, sino como un actor en sí mismo que por derecho propio desempeña una función preponderante y muestra liderazgo.

Este nivel de actuación es el tópico central del presente artículo. ${ }^{1}$ Como bien indica Pécoud, hasta muy recientemente la OIM había sido poco investigada y más todavía desde los enfoques teóricos: «Prácticamente ningún estudio examina a la OIM desde una perspectiva de las Relaciones Internacionales (IR, por sus siglas en inglés)» (Pécoud, 2018:1623). Por ejemplo, en el volumen sobre la gobernanza migratoria mundial, publicado por Alexander Betts, muchas contribuciones la mencionan, pero en su mayoría de modo descriptivo y superficial (Betts, 2011a). Aunque en la introducción y en la conclusión se ahonda un poco más en la organización mediante un enfoque de las IR, su actuación es muy limitada. Para Betts, «existe principalmente como un proveedor de servicios para los Estados, que trabaja en proyectos específicos de acuerdo con las exigencias y prioridades de los Estados donantes», en múltiples sentidos, su enfoque "se acerca más a una empresa privada que a una organización internacional típica», además "carece de visión normativa propia» (2011b:13).

Considero que, si bien estas caracterizaciones abarcan facetas importantes de la OIM, podemos obtener una visión más completa de la organización al examinar su papel en los diferentes niveles de la emergente gobernanza mundial migratoria. Al respecto, en una primera sección discutiré la literatura acerca de la agencia de las organizaciones internacionales. Ello seguido de un análisis de las estrategias empleadas por la OIM hacia múltiples actores y foros como el UN-HLD, el FMMD y las deliberaciones sobre el Pacto Mundial para una Migración segura, ordenada y regular (PMM). En la conclusión discutiré otros campos de estudio.

\footnotetext{
${ }^{1}$ Versiones anteriores de este documento fueron presentadas en la conferencia «Gestión de la migración en la sociedad mundial. Organizaciones internacionales en política migratoria II», Universidad de Carleton, Ottawa, en marzo de 2017 y en la conferencia general del Consorcio Europeo para la investigación Política (ECPR, por sus siglas en inglés), Wroclaw, Polonia, en septiembre de 2019. Agradezco a todos los participantes y ponentes por su retroalimentación.
} 
Los hallazgos se fundamentan en el análisis exhaustivo de documentos, entrevistas y observación participante en foros mundiales como el FMMD (todas las reuniones desde el 2008), el UN-HLD (2013) y la «Semana de la migración» 2018 en Marruecos, incluida la Conferencia Intergubernamental sobre el Pacto Mundial para la Migración.

\section{Organizaciones internacionales como actores}

A partir de acontecimientos actuales en la política internacional se ha puesto en tela de juicio a las organizaciones internacionales, por no afirmar que su autoridad se encuentra en declive: comprende desde los países del grupo Visegrád de la Unión Europea (UE), que se rehúsan a aceptar las decisiones de la organización regional, aunado a la drástica decisión del brexit, hasta la administración de Donald Trump que se aleja de la Organización Mundial del Comercio (OMC), de la ONU y de prácticamente todo tipo de acuerdos multilaterales y organizaciones internacionales. Sin embargo, según un estudio reciente «las organizaciones internacionales se han vuelto más autoritarias en las últimas décadas, es decir, ahora dependen menos del control de los miembros individuales» (Lenz, 2017:1; Hooghe et al., 2017). Un indicador de este desarrollo es percibido por los analistas con respecto a la creciente extensión, en la que los Estados recurren a cualquiera de las dos agrupaciones (apoyan las formas mayoritarias en la toma de decisiones) o a la delegación (empoderan a instituciones independientes para que actúen en su nombre). Cabe mencionar que la OIM ocupa un lugar intermedio en la delegación y uno alto en la agrupación (Lenz, 2017:1; Hooghe et al., 2017); ello es característico de las organizaciones bajo estudio que cumplen tareas específicas. Las razones del incremento en la autoridad internacional son visibles en la búsqueda funcional de una cooperación efectiva, los actores no gubernamentales exigen cada vez más la participación política y «la difusión de modelos institucionales autoritarios entre las organizaciones internacionales» (Lenz, 2017:1).

Este amplio estudio empírico contribuye a lo que se considera un giro organizacional en la teoría de las IR (Ellis, 2010). A pesar de que en la teoría organizacional el organismo inherente y la autonomía de las organizaciones internacionales son en gran medida indiscutibles, predomina todavía la controversia en la teoría de las IR centradas en el Estado. David C. Ellis observa «una inconsistencia intelectual en la beca de las IR que valora a los Estados, pero no a las 
organizaciones internacionales, como actores unitarios, cuando en realidad ambos son entidades corporativas» (Ellis, 2010:12). En otras palabras, el planteamiento de la investigación sobre los Estados como actores en el sistema internacional debería también aplicarse a las instituciones internacionales. En su clásico libro Man, the state and war, Kenneth Waltz (2001) introdujo tres imágenes de análisis que explican los orígenes del conflicto en el sistema internacional. La primera imagen examina el papel de los líderes; la segunda, la estructura interna y el conflicto de los Estados; y la tercera (más desarrollada en trabajos posteriores), el sistema internacional.

Apoyado en la jerarquía de los niveles de las organizaciones de Joel A. Baum y Tim J. Rowley (2007), Ellis sugiere que las imágenes previas podrían utilizarse para los niveles de análisis correspondientes a las organizaciones internacionales: la primera se enfocaría en el análisis intraorganizacional y revisaría la función de las secretarías, consejos o comunidades epistémicas (empero, yo estimaría que la última no siempre encaja perfectamente en la dimensión interna, pues es probable que haya vínculos con el «mundo exterior»). La segunda podría basarse en el análisis organizacional y comprendería desde la negociación intrasistémica hasta los modelos de financiación, las normas de votación y la interacción de las OI con los Estados y las Organizaciones no Gubernamentales (ONG). La tercera encuentra su equivalente en el análisis interorganizacional, el cual puede centrarse en la estructura del sistema internacional, las redes de las organizaciones internacionales con otras y las ONG, así como el papel de las normas y los agentes de cambio. Un análisis que se reduce a todos los niveles sería el de la dimensión del aprendizaje institucional, mismo que se relaciona con la difusión de los modelos exitosos citados.

El creciente interés en las organizaciones internacionales se manifiesta en distintas publicaciones, entre ellas la serie de libros Global Institutions, probablemente la más completa. Después de concluir este artículo, se publicó una monografía dedicada a la OIM (Bradley, 2020). Antes —además de un volumen editado sobre la industria migratoria (Gammeltoft-Hansen y Sørensen, 2013)—, es notorio que la única institución asociada con la migración, y que adicionalmente había recibido una atención significativa en la serie, fue el Alto Comisionado de las Naciones Unidas para los Refugiados (ACNUR) dentro de una monografía (Deardorff, 2017) y en un capítulo del libro International organizations as self-directed actors (2012a), de Joel Oestreich, el cual proporciona un marco analítico pertinente para la OIM. 
Oestreich responde a los principales enfoques en la teoría de las IR, los cuales asumen que son los Estados los que actúan, a través del trabajo de las organizaciones internacionales que crean. Tales supuestos provienen de «realistas tradicionales que ven a las organizaciones internacionales como cuerpos sin sentido en un mundo de actores estatales, fundados en la teoría liberal; paralelamente, admiten su influencia en la política mundial como lugares de normas y expectativas sociales, pero no como agentes con sus particulares necesidades y deseos, y la capacidad de actuar sobre ellos» (2012b:1). Por otra parte, el constructivismo examina la creación y la difusión de normas en el sistema internacional, éstas podrían no sólo flotar en el ambiente sino también manifestarse en una forma más concreta como las organizaciones internacionales.

La posición ontológica de Oestreich y sus coautores es «que las organizaciones internacionales existen independientemente de los Estados y tienen un efecto propio que las convierte en materia de distintas maneras» (Oestreich, 2012b:5). Una forma de analizarlas como actores es la teoría del agente principal, con organizaciones internacionales contratadas al servicio de los intereses de los Estados, que delegan tareas que no pueden o no quieren realizar por sí mismas (Hawkins et al., 2006). Incluso si en ese escenario fungen como «servidoras», no obstante son actores que tratan asuntos en nombre de otros. Asimismo, en el devenir los servidores pueden desarrollar su propia mentalidad e intereses. Dichos intereses quizá no estén del todo alineados con los principios, en específico cuando hay una «laxitud» en la supervisión: "La teoría del agente principal y el trabajo en el comportamiento burocrático determinan que el objetivo primordial de las burocracias es su expansión: la expansión de presupuestos, de los poderes y de su existencia a lo largo del tiempo» (Oestreich, 2012b:7; Brehm y Gates, 2002). Esta tendencia se ilustra ampliamente en múltiples niveles, desde los departamentos gubernamentales nacionales hasta las guerras territoriales de las organizaciones internacionales en general y en particular de las agencias de la ONU. Las organizaciones llegan a acentuar su «laxitud» al emplear información asimétrica (por ejemplo, sus conocimientos especializados) en su beneficio, o bien, si sus directivos son numerosos y no existen entre ellos intereses unificados (Oestreich, 2012b:7). Valorar a las organizaciones internacionales como entidades corporativas centraría el análisis en la estructura interna de las organizaciones, los intereses de las personas que ahí trabajan, sus ramas y sus líderes.

Con base en una visión constructivista relativa a la teoría del agente principal, es posible detectar indicadores respecto a que la relación entre los Estados 
y las organizaciones internacionales se asemeja cada vez más. Estas últimas pueden utilizar su control sobre el poder y los recursos burocráticos para influir en el comportamiento del Estado y que los Estados puedan «entonces involucrarse en una relación intersubjetiva con las organizaciones internacionales e inevitablemente, conforme cambia su identidad, afectar sus propios intereses» (Oestreich, 2012b:8). El poder, la influencia y, hasta cierto punto, la independencia - por no decir la autonomía de las organizaciones internacionales-, derivan en específico de las ideas, el conocimiento y los discursos. Las organizaciones no sólo ejecutan órdenes de manera burocrática, pueden también «servir como vías para propagar ideas globalizadas o globalizadoras, pues captan, internalizan $y$ difunden concepciones que forman parte de su entorno operativo, en la medida en que dichas concepciones parecen armonizar con el mandato de la burocracia» (Oestreich, 2012b:9). Lo anterior es un proceso fluido en el que el ámbito internacional y otros actores como las comunidades epistémicas cumplen su papel en la configuración de esas ideas. Por ende, las organizaciones internacionales no pueden analizarse de modo aislado, es preciso tener en cuenta la red o redes de las que forman parte.

\section{Investigación de la OIM como actor en las relaciones internacionales}

خDe qué modo contribuyen los aludidos enfoques teóricos para investigar a la OIM como un actor? Probablemente el enfoque con el mayor potencial es al mismo tiempo uno de los más difíciles, esto es, intentar revisar de forma sistemática el interior de la «caja negra» de la organización internacional. Cuando se trata de su funcionamiento interno la OIM es notoriamente hermética, según lo atestiguaron diversos investigadores en conversaciones con el autor, quienes han pretendido acercarse a la organización a fin de solicitar datos concernientes al manejo de casos, finanzas, etcétera. Con todo, una etnografía organizativa sería de mucha utilidad. Por vez primera, la realización de un análisis cimentado en los niveles de organización —o «imágenes»— podría arrojar luz sobre la compleja dinámica interna de la organización que, por un lado, posee un fuerte centro con su sede en Ginebra y representación en la ONU y, por otro, lleva a cabo gran parte de su trabajo in situ con una plétora de oficinas y programas nacionales, subnacionales y regionales, además de centros administrativos, 
oficinas especiales de enlace, así como el Fortalecimiento de la Capacidad Africana (ACBC, por sus siglas en inglés) y el Centro de Análisis de Datos de la OIM sobre la Migración Mundial (GMDAC, por sus siglas en inglés).

La función que la OIM cumple con los países de origen, tránsito y destino, ha sido revisada por distintos autores (Geiger, 2018; Barber y Bryan, 2018; Fine, 2018; Dini, 2018); un siguiente paso sería ahora situar estos hallazgos dentro de un análisis más vasto referente a la interacción entre los niveles intraorganizacional, organizacional e interorganizacional. ¿̇Cómo se vinculan los principios de la OIM en el lugar, cómo afectan los resultados (positivos o negativos) de los proyectos mencionados a la estrategia general de la organización? ¿Qué efecto tiene la crítica de la sociedad civil en los programas que violan los derechos humanos de los migrantes (Andrijasevic y Walters, 2010:980)?

Un tema común de la literatura sobre la actuación de las organizaciones internacionales es la relevancia de las personas que trabajan en ellas. Así, en un afán de comprender en su totalidad las acciones de la OIM es importante incluir el papel del director general, quien tradicionalmente ha sido exdiplomático de Estados Unidos. El anterior director, William Lacy Swing, luego de ser embajador de Estados Unidos, desempeñó diferentes funciones dentro de la ONU, hecho que con seguridad influyó en las negociaciones para acercar a la organización a dicho sistema. Derivado del cambiante entorno internacional, al momento de elegir a su sucesor, no se consiguió la mayoría para el controvertido candidato estadounidense. En contraposición, el político portugués, António Manuel de Carvalho Ferreira Vitorino, anterior comisionado europeo de Justicia y Asuntos Internos, fue elegido en junio de 2018 y en la actualidad funge como director general. La impresión inicial tentativa, después de sus dos primeros años en el cargo, estriba en su voluntad para abrir a la organización a discursos provenientes de actores sociales, particularmente de la sociedad civil, y lograr así una mayor participación en la ONU.

El análisis no debe detenerse, incluso debe tener en cuenta a las personas en el lugar. Aquí, la OIM parece estar lejos de ser una entidad uniforme, con diferentes grupos de proyectos, una alta fluctuación del personal en algunas oficinas y la subcontratación de expertos para la ejecución de proyectos. Si bien este estudio podría perjudicar la dicotomía percibida, referente a cuál es la organización internacional «buena» y cuál es la «mala» en términos de migración, raramente existe consenso entre la sociedad civil y los investigadores críticos. Traigo a colación el comentario que hizo uno de mis encuestados en tono de 
burla: "La OIT es una organización bien intencionada donde trabajan algunas personas cuestionables; la OIM es una organización cuestionable donde trabajan ciertas personas bien intencionadas» (intercambio informal durante el GMDAC en Daca, Bangladés, 10 de diciembre de 2016).

Es evidente que una investigación tan completa es fácil de demandar y difícil de implementar, por esa razón sigue siendo un objetivo a largo plazo. ${ }^{2}$ Un análisis más profundo de las «relaciones externas» de la organización puede ser visto como un paso hacia ello, y con este fin la siguiente sección se centrará en los niveles interorganizacional/internacional y en la búsqueda de la OIM para conseguirlo.

\section{La OIM en la gobernanza mundial de la migración}

Los partidarios de "la letra pequeña» sin duda disfrutarán del párrafo 49 de la Declaración de Nueva York para los Refugiados y los Migrantes:

Nos comprometemos a fortalecer la gobernanza mundial de la migración. Por ello, apoyamos y acogemos con beneplácito el acuerdo de llevar a la Organización Internacional para las Migraciones, una organización considerada por sus Estados miembro como el organismo líder mundial en migración, en una relación jurídica y de trabajo más estrecha con las Naciones Unidas como organización conexa (énfasis añadido) (Asamblea General de las Naciones Unidas, 2016:715).

Obviamente, este párrafo elude la manera en que la Asamblea General de la ONU considera a la OIM al referirse a la autoimagen de la organización con el respaldo de sus Estados miembro. Asimismo, en el acuerdo de cooperación concerniente a la relación entre la ONU y la OIM se establece en los principios del artículo 2: «Las Naciones Unidas reconocen a la Organización Internacional para las Migraciones como una organización con un papel de liderazgo mundial en el área de la migración».

Tal como informó un observador del proceso de negociación: «Debido a las objeciones de otros organismos, el acuerdo no designó a la OIM como «el organismo líder mundial en migración', sino que tenía un ‘papel principal»» (conversación 
por correo electrónico el 27 de julio de 2016; para mayor información véase Weiss y Micinski, 2016:3).

Al principio, esto pudiera parecer mera semántica; no obstante, al considerar que 28 componentes diferentes de la ONU se ocupan de la migración (Weiss y Micinski, 2016), el hecho de que se le asigne «un» o «el» papel principal tiene consecuencias potencialmente de largo alcance en cuanto a autoridad, responsabilidad y, por supuesto, prestigio. En consonancia con la tendencia discutida previamente, no debe soslayarse la expansión continua de la existencia y el poder de las burocracias. En un inicio, conseguir el estatus poco utilizado de un organismo asociado en realidad no cambió mucho en la práctica, básicamente extendió la anterior relación OIM-ONU: «Aunque la OIM disfruta ahora de un asiento en la alta mesa de la ONU para la formulación de políticas, antes apenas si tenía influencia - en particular en los mecanismos de coordinación, los grupos de trabajo regionales y los planes conjuntos de respuesta» (Weiss y Micinski, 2016:3).

En ese sentido, la OIM aprovechó el potencial aumento de prestigio a través del nuevo acuerdo: elidió la parte «conexa» en el trayecto y ahora se refiere, casi obsesivamente, a sí misma en todos sus comunicados de prensa y declaraciones como «OIM, Agencia conexa de Naciones Unidas para la Migración», además añadió la descripción a su logotipo. Ello puede apreciarse como una continuación de la sed de reconocimiento resaltada en los tweets citados al inicio de este capítulo - y, en consecuencia, en Twitter la (es decir, nombre de usuario) la «cuenta oficial de la \#OIM, la Agencia de las Naciones Unidas para la Migración» se ha cambiado de inmediato a@UNmigration.

Si bien este enfoque puede haber parecido absurdo a algunos observadores en ese momento, a la vez es un punto de referencia importante en la búsqueda de actores de la OIM. En opinión de Pécoud (2018), la historia de dicha organización es una metamorfosis recurrente, con distintos cambios de nombres y mandatos antes de que alcanzara su forma actual (su creación se estableció en 1989). El final de la Guerra Fría marca, asimismo, la transición de la OIM como un proveedor de servicios a un agentey, después, a una organización con mayor independencia, por encima de la relación del agente-principal. Casi desde el comienzo este proceso estuvo marcado por una cooperación muy estrecha con la ONU: en 1992 la OIM se convirtió en un observador permanente en la Asamblea General. A esto le siguió un acuerdo formal de cooperación en 1996 y un memorándum de entendimiento (MDE) en 2013, situación que fue preparando el terreno para su estatus actual como agencia conexa. 
En efecto, hasta hoy su núcleo sigue siendo su trabajo basado en proyectos, pues de ahí proviene la parte abrumadora de su financiación. Eso no significa que haya una tensión entre la proyección y su propósito de ser reconocida como un actor en la gobernanza mundial: por el contrario, aparte de ser un objetivo en sí mismo para las burocracias, el prestigio mundial también es «positivo en los negocios» y puede propiciar la adquisición de más proyectos en los «mercados interconectados» que las organizaciones internacionales están tratando de establecer.

Al observar las políticas y actividades de la OIM en los últimos 20 años parece haber una serie de estrategias dirigidas a múltiples actores sociales con el objetivo de promoverse. Acorde con las perspectivas constructivistas, me concentro en las ideas y los discursos detrás de estos planteamientos. Los principales interesados son los Estados, el nivel regional, lo público que incluye medios de comunicación y academia, otras organizaciones internacionales y el entorno de la gobernanza mundial; así como, últimamente, la sociedad civil migrante.

Estrategias para los Estados y las organizaciones regionales, y el papel del conocimiento

Aunque el nuevo estatus de la OIM destaca su «naturaleza no normativa», es posible identificar específicas normas y paradigmas de la organización. El principal difícilmente podría ocultarse, puesto que se proclama justo en su lema: "Gestión de la migración para el beneficio de todos» (Centro de Información de las Naciones Unidas, s/f). Dicho paradigma y sus beneficiarios reales han sido cuestionados y criticados en la investigación (Geiger y Pécoud, 2010; Ashutosh y Mountz, 2011; Delgado, 2018) y entre los activistas, pero eso no ha disminuido su interés en los Estados. Aunado a ello, sostiene que la migración puede tratarse de manera tecnocrática y centralizada por los Estados y las instituciones internacionales; atribuye además a los migrantes el papel de «objetos» de estos esfuerzos de gestión y les niega la representación (Piper y Rother, 2012:1737) — después de todo, la OIM es una organización «para la migración, no (principalmente) «para los migrantes» y un enfoque basado en los derechos de la migración no es una prioridad en su agenda.

El atractivo primordial de la norma o paradigma de gestión migratoria hacia los Estados radica en el énfasis de la primacía de estos últimos, la noción de 
territorialidad y la defensa del orden westfaliano. En ese sentido, cuando los Estados - y las organizaciones regionales como la UE- elogian constantemente a la OIM, no sólo prometen apoyo a la organización, sino también a la conceptualización estatal de la gobernanza migratoria que representa (y, en cierto sentido, para sí mismos). Lo anterior puede ser un indicador de que la organización es simplemente un buque que transporta los intereses de los Estados; no obstante, yo diría que este paradigma ha tomado vida propia más allá de la relación principal-agente.

De forma complementaria, hay una dependencia cada vez mayor de los Estados de la OIM debido a su producción de conocimiento hegemónico; Oleg Korneev lo denomina una estrategia de autolegitimación al ser valorada como la única fuente de conocimiento autorizado (2018:1686). Esto se relaciona con la estrategia antes mencionada de las organizaciones internacionales que utilizan información asimétrica a su favor y aumentan su «laxitud». Aparte de la experiencia adquirida en el curso de numerosos proyectos, el GMDAC de la OIM se estableció en 2015 en Berlín como una fuente adicional de ese conocimiento. De hecho, la demanda a «mejores datos migratorios» se ha convertido en los últimos años casi en un mantra en el contexto del debate sobre desarrollo migratorio; adicionalmente, se cuestiona el supuesto vínculo entre mejores datos y mejores políticas migratorias, ya que éstas a menudo se basan más en la percepción de la opinión pública, la esperanza de ganancias electorales, las ideologías, etcétera.

Tal como han apuntado Stephan Scheel y Funda Ustek-Spilda (2019), el énfasis en los datos (cuantitativos) se encuentra en consonancia con la estrategia de gestión migratoria de la OIM: «Permite a organismos como la OIM presentarse como actores competentes con la experiencia para entregar proyectos de gestión migratoria», la forma en la que se representa el conocimiento identifica «a la migración como una realidad única, coherente y, por tanto, cognoscible y manejable, reproduce así una de las mismas doxas del ámbito de la gestión migratoria» (Scheel y Ustek-Spilda, 2019:665). En un análisis de la Matriz de Seguimiento de Desplazamiento (DTM, por sus siglas en inglés) de la OIM, Max Cohen y Saskia Llewellyn (2019) critican la naturaleza apolítica de la presentación de datos, donde «las subjetividades y organismos clasificados son borrados, mientras se prestan como objetos de control global», concluyen que «en su lucha por convertirse en la sautoridad epistémicas, en cuanto a la producción de conocimiento acerca de la migración, la OIM puede pasar por alto consideraciones 
éticas y políticas cruciales con respecto a la producción de datos migratorios» (énfasis en el original).

El conocimiento precedente no se comparte de manera exclusiva con los países que financian los proyectos de las organizaciones, es decir, predominantemente los de destino; es también la base para el apoyo o la capacitación en los países de origen. La OIM ha sido muy activa en la creación y la organización de los Procesos Consultivos Regionales (PCR) —en su mayoría reuniones informales y no vinculantes en las que la primera etapa se centra por lo general en el establecimiento de la agenda y la definición de temas (Hansen, 2010:9). Ello proporciona una plataforma adicional para que promueva su enfoque de gestión. Durante el FMMD en Ecuador (21 de enero de 2020), el presidente entrante de los Emiratos Árabes Unidos organizó un evento paralelo en la misma fecha, FMMD de 2020: Participación de Mecanismos Consultivos Regionales y Grupos de Interesados en el Lanzamiento de Asociaciones. ${ }^{3}$ En este caso, con una parte representativa de la OIM del panel, los PCR, dirigidos por la OIM, se exhibieron como los foros más adecuados en cuanto a consultas previas a la cumbre, programada para enero de 2021 en Dubái. De nuevo, el enfoque se abre al debate porque para el Sudeste Asiático el Proceso de Bali fue elegido como el PCR apto - empero el objetivo de ese proceso no se centra en el desarrollo sino en «el tráfico de personas, trata de personas y la delincuencia transnacional conexa» (Proceso de Bali, 2018). Aunque el Foro de la ASEAN sobre el Trabajo Migratorio (AFML, por sus siglas en inglés) podría haber tenido un mejor ajuste temático (Rother, 2018), la fuerza básica externa detrás de él es la OIT. Planteado en estos términos, se trata de un caso de intereses institucionales que priorizan las consideraciones asociadas con el contenido.

\section{Difusión pública}

A pesar —o derivado quizá - de su renuencia al escrutinio público, la OIM ha estado cada vez más activa en la esfera pública mundial. Como se mostró al inicio, antes que otras organizaciones reconoce la importancia de las redes sociales. William L. Swing, por ejemplo, se ha convertido en una figura pública con mayor visibilidad que los directores de organizaciones como la OIT y el ACNUR. En discursos, mesas redondas y entrevistas se pronunció en contra de

\footnotetext{
${ }^{3}$ Véase https://www.gfmd.org/files/documents/se_uae.pdf
} 
la xenofobia y a favor de la protección de los migrantes, emitió además su mantra relativo a que "la migración no es un problema a resolver, sino una realidad humana que debe gestionarse» (OIM, 2015). Inclusive, ahora existe un Festival Mundial de Cine sobre la Migración y una de las campañas más grandes de la organización se denomina «Soy migrante» — una "plataforma para promover la diversidad y la inclusión de los migrantes en la sociedad. Está diseñada específicamente para apoyar a grupos de voluntarios, autoridades locales, empresas, asociaciones, grupos, de hecho, cualquier persona de buena voluntad que esté preocupada por el discurso público hostil en contra de los migrantes». Sara de Jong y Petra Dannecker sostienen que esta campaña «no es antitética a la misión de la OIM de gestionar la migración de acuerdo con una lógica de productividad y racionalidad, sino más bien es una extensión lógica de la misma» (2017:75).

La producción de conocimiento forma parte de esta difusión y la OIM es fuente de numerosos informes dirigidos a profesionales y académicos que los emplean como valiosa información, aunque tienden a contribuir a despolitizar el asunto migratorio. Pécoud insiste que tal estrategia se logra a través de la confianza en términos ambiguos, del desarrollo de argumentos en el nivel abstracto sin tomar posiciones claras, de la dependencia tecnocrática empírica, y de la indiscutible «naturalización del contexto socioeconómico y político global en que ocurre la migración» (2015:95). Relativo a la migración, la OIM está más conectada con la comunidad epistémica, mediante la puesta en marcha de informes de sus integrantes o invitándolos como oradores, por ejemplo, en su escuela de verano anual sobre migración en Praga. ${ }^{4}$ Tampoco es inusual que su personal escriba acerca de su organización en volúmenes publicados (véase Potaux, 2011). Un intento reciente de atraer a la comunidad investigadora ha sido la creación del algo ostentosamente titulado "Sindicato líder de la investigación migratoria» en apoyo al PMM de diciembre de 2018. En un primer paso, se solicitó a los integrantes del sindicato que proporcionaran sus «tres mejores lecturas», las cuales, como era de esperar, resultaron ser sus propios escritos. Se encargaron y presentaron artículos técnicos en un taller en Ginebra centrados en dos aspectos fundamentales: «a) Articular las interrogantes que existen actualmente en torno de la gestión migratoria internacional, b) sugerir la forma más conveniente de conciliar estas interrogantes de manera práctica y sostenible» (McAuliffe y Klein, 
2017a:3). A pesar de esta fuerte orientación de gestión y políticas prácticas, además de distintas actividades como «apoyar comunidades sedentarias» $\mathrm{y}$ «combatir el contrabando», se prestó cierta atención a los derechos de los trabajadores migrantes y en qué medida pueden fortalecerse - aunque «sin reducir el acceso a los mercados laborales de otros países» (McAuliffe y Klein, 2017a:3). Posterior a la publicación de los artículos (McAuliffe y Klein, 2017a:3), la iniciativa parece haberse vuelto inactiva con la adopción del PMM.

\section{La OIM como actor en la gobernanza migratoria mundial}

Acorde con la tendencia de las organizaciones internacionales a expandirse, la OIM ha ampliado su expediente para incluir temas que se han puesto de moda en décadas recientes, entre ellos el supuesto nexo entre migración y desarrollo (Castles y Delgado, 2008), el cambio climático y la migración, y en general la gobernanza migratoria mundial. El discurso sobre migración-desarrollo se adapta en particular a la organización, ya que permite concentrarse en los aspectos positivos de la migración y en las historias exitosas, sin tener que comprometerse con discursos basados en los derechos (Piper y Rother, 2014). Asimismo, el foro derivado del «mantra» migración-desarrollo con su, al menos inicialmente, fuerte énfasis en las remesas (Kapur, 2003) concuerda con el enfoque de la OIM para la gobernanza migratoria: el FMMD es un proceso estatal, no obligatorio e informal centrado en las «mejores prácticas» (Rother, 2010). Comenzó como un foro de diálogo y un ejercicio de fomento de la confianza (Rother, 2019), el proceso ha conseguido presencia a través de la inclusión de la migración en los Objetivos de Desarrollo Sostenible (ODS) (Piper, 2017).

La OIM ha desempeñado una función muy activa en la parte del FMMD dedicada a la Reunión del Gobierno: proporciona documentos de apoyo, facilita oradores para las mesas redondas sobre distintos tópicos como «Perfiles Migratorios», "Comparación de los marcos de movilidad Sur-Sur», "Empoderamiento de los migrantes al garantizar su salud y bienestar», por citar algunos. Complementariamente, se ha unido a otras organizaciones en diversos programas, donde ocupa un destacado lugar al interior del FMMD, OIM-PNUD Incorporación de la Migración al Programa de Estrategias Nacionales de Desarrollo desde 2011 y la Iniciativa Conjunta de las Naciones Unidas para la Migración y el Desarrollo, hecho que de ninguna manera la ha limitado (OIM, 2017a). Como se preveía, este aporte se fundamenta en la implementación de programas, su 
integración, una "visión de todo el gobierno» y la recopilación de datos con poca conceptualización de una perspectiva más integral para el desarrollo y las causas profundas del subdesarrollo. Cabe mencionar que la OIM alberga la pequeña secretaría permanente del FMMD (organizada en gran medida por diferentes países receptores y foros de apoyo).

En paralelo, la OIM contribuyó a los dos UN-HLD en 2006 y 2013, esta participación le otorgó un papel importante en las deliberaciones sobre el PMM (el título se basa en los principios de los ODS). La gama de actividades llevadas a cabo por la organización son un claro indicador del nivel de representación alcanzado por ella; define su función en términos de «trabajar para movilizar a los Estados miembro e involucrar diversos actores sociales para asegurar que todas las voces se escuchen en el establecimiento de la agenda migratoria mundial de los años venideros, y (...) proporcionar su experiencia técnica y normativa para apoyar el proceso del PMM, como se requiere en la resolución de modalidades» (OIM, 2017b). Las actividades comprenden los documentos temáticos; las consultas nacionales; la participación de la sociedad civil en los PCR (como se verá más adelante); los Diálogos Internacionales sobre Migración de 2017, su principal foro de diálogo político para los Estados miembro y observadores, así como organizaciones asociadas al pacto mundial; el sindicato líder en investigación y la difusión en los medios de comunicación mencionados.

La OIM publicó una «visión» del PMM, en la que los derechos de los migrantes poseen mayor relevancia que en documentos anteriores:

El pacto mundial presenta una oportunidad histórica para lograr un mundo en el que los migrantes se desplacen por elección y no por necesidad, a través de canales seguros, ordenados y regulares, y en el que la migración esté bien gobernada y sea capaz de actuar como una fuerza positiva para las personas, las sociedades y los Estados. La OIM prevé un pacto mundial que situé los derechos, las necesidades, las capacidades y las contribuciones de los migrantes en su núcleo, con miras a garantizar su seguridad, dignidad y derechos humanos (OIM, 2017c).

Para materializar esta visión, la OIM sugiere basarse en tres principios del Marco de Gobernanza Migratoria, adoptados por sus Estados miembro como marco general para la gobernanza migratoria: adhesión a las normas internacionales y el cumplimiento de los derechos de los migrantes, enfoques basados en la evidencia y de todo el gobierno, fomento y apoyo en sólidas asociaciones (OIM, 2017c). 
En la actualidad, la OIM está forjando su papel en la implementación del PMM. Igualmente, se le ha asignado una función crucial en la recién establecida Red de las Naciones Unidas sobre Migración: «La OIM actuará como coordinadora y secretaría de todas las partes constitutivas de la red» (s/f). La red se encuentra todavía en sus primeras etapas, no sólo por lo que concierne a la coordinación (el director general de las organizaciones o su designado), sino por dotar de personal a la secretaría de la red (la organización «también estaría abierta a la adscripción de colaboradores de la ONU»), es indudable que la OIM tiene una fuerte influencia en el proceso. Después de que el ahora obsoleto Grupo Mundial sobre Migración (GMM), no haya logrado políticas coherentes entre sus organizaciones miembro, la red tiene la encomienda de lograr «apoyar una acción coherente de la ONU a escalas nacional, regional y mundial en apoyo de la implementación del GMM, en la que esa acción añadiría valor, a la vez que se garantizarían vínculos bien definidos con las estructuras de la ONU en cualquier nivel» (OIM, 2017c). Asimismo, la red ha establecido el Fondo Fiduciario de Asociados Múltiples (MPTF, por sus siglas en inglés) para financiar la acción colectiva en la implementación del PMM. Pese a que todavía es pronto para evaluar las perspectivas de la red, se puede decir como observación inicial que ha comenzado a mejorar la comunicación de proyectos conjuntos por parte de sus miembros. Por ejemplo, una declaración sobre covid-19, emitida el 20 de marzo de 2020, lanzó un mensaje bastante fuerte contra la xenofobia bajo el título "El covid-19 no discrimina; tampoco debería hacerlo nuestra respuesta» (Red de las Naciones Unidas sobre Migración, 2020). La declaración fue aprobada por representantes y activistas de la sociedad civil durante dos reuniones sostenidas con la «Red de Sesiones de Interlocución de la ONU, interesados en la crisis de la covid-19 y migrantes», celebrada el 1 de abril de 2020. Éstas fueron organizadas por el Oficial de Enlace de la Sociedad Civil de la red, Monami Maulik, un activista de los derechos de los migrantes desde hace mucho tiempo, ahora también con cargo en la OIM, aunque independiente. Dichas actividades coinciden con la creciente interacción entre la organización y la sociedad civil migrante.

\section{La OIM y la sociedad civil migrante}

Si bien la OIM ha sobresalido notablemente en la parte gubernamental de las reuniones del FMMD, durante varios años tuvo una presencia menor en las 
jornadas de la sociedad civil del foro. Situación que puede atribuirse a una desconfianza generalizada entre los activistas hacia la organización, quienes la consideran un agente de políticas neoliberales debido a la mercantilización del trabajo; la gestión de las fronteras; las deportaciones disfrazadas de retornos voluntarios; y las malas prácticas en el lugar, como el campo de detención australiano (críticas reunidas en numerosos eventos de la sociedad civil; véase también Rother, 2013). En el FMMD de 2016 en Bangladés y en la reunión de 2017 en Berlín, Alemania, la OIM se involucró más en estas jornadas de la sociedad civil, en particular como especialista en el pacto mundial. Representantes de la sociedad civil han planteado ciertos desafíos: en Berlín, hubo llamados a «pensar en una nueva OIM» y a promover un mandato de protección de la organización.

Aun así, resulta obvio que la sociedad civil es la siguiente en la fila de los actores sociales a los que la OIM intenta acercarse. Ello se palpa en la creciente noción de derechos humanos en los documentos de las organizaciones y en la designación de Colin Rajah, un activista de los derechos de los migrantes desde hace un largo tiempo, como su centro de enlace con la sociedad civil con el afán de "facilitar la participación de los líderes de la sociedad civil durante las consultas para el PMM» (OIM, 2017d). La OIM organizó cinco audiencias interactivas informales para múltiples interesados, bajo la modalidad de grupos pequeños. Se efectuaron entre octubre de 2017 y julio de 2018 en Ginebra y Nueva York. El oficial de enlace de la sociedad civil de la OIM describió su papel en el proceso: "Garantizar que la sociedad civil pueda tener el máximo compromiso posible a lo largo de las negociaciones» (entrevista con Rajah, 4 de marzo de 2019). Los representantes de las organizaciones mundiales de los derechos de los migrantes apreciaron la financiación y el apoyo de la organización; sin embargo, se mantuvieron cautelosos para no ser cooptados: «Establecimos un cortafuegos entre el lado hermético de la OIM, y su lado institucional y operativo» (entrevista con activista, 5 de marzo de 2019) — lo que significa que los representantes de la sociedad civil no fueron influenciados por la financiación con respecto a su crítica de las operaciones de la OIM en el lugar y a escala regional. Las organizaciones de la sociedad civil promovieron, de igual modo, sus propias estructuras consultivas, construyeron alianzas con Estados afines y produjeron insumos independientes para el pacto (Rother y Steinhilper, 2019). 


\section{Conclusión}

Previamente se discutió que un análisis de la OIM como mero proveedor de servicios e instrumento de los intereses de los Estados corre el riesgo de ignorar aspectos esenciales. Con base en datos sobre las relaciones internacionales y la teoría de la organización es posible captar en su totalidad los múltiples niveles de estructura y participación de la OIM. Sin duda, puede ser considerada un actor en la gobernanza migratoria mundial con un grado de independencia que trasciende la relación entre el representado y el representante. Lo anterior es visible sobre todo en su injerencia en las deliberaciones del pacto mundial, donde definió su papel en la movilización de sus Estados miembro y en la comunicación con distintos actores sociales.

En las dos últimas décadas la relación con los grupos de interés ha sido determinante en el aumento de representación de la OIM, en particular la expansión temática en torno de aspectos concretos: migración y desarrollo, migración climática y gobernanza migratoria mundial en general. Con todo, es indispensable vislumbrar si esta estrategia acabará incorporando más plenamente a la organización a la ONU - una sugerencia que se remonta a la Comisión Mundial sobre las Migraciones Internacionales (CMMI) de 2015, y que planea fusionar la OIM y el ACNUR en una Organización Mundial para los Refugiados y los Migrantes (Baldwin-Edwards, 2005; Global Comission on International Migration, GCIM, 2005). Aunque la OIM ha dejado su impronta en los diversos debates y procesos mundiales, existen indicadores de que se trata de un proceso bidireccional; un análisis exhaustivo debería centrarse en la forma en que la organización podría socializar mediante esta interacción con una gama más amplia de grupos de interés y la exposición a discursos críticos.

\section{Agradecimientos}

El autor agradece a la Sociedad Científica de la Universidad de Friburgo por apoyar su participación en el Foro Mundial sobre Migración y Desarrollo (FMMD) 2020 en Quito, Ecuador. 


\section{Referencias}

Andrijasevic, Rutvica y William Walters (2010), «The International Organization for Migration and the International Government of Borders», Environ Plan D, 28(6), pp. 977-999. DOI: 10.1068/d1509.

Ashutosh, Ishan y Alison Mountz (2011), "Migration management for the benefit of whom? Interrogating the work of the International Organization for Migration», Citizenship Studies, 15(1), pp. 21-38. DOI: 10.1080/13621025.2011.534914.

Baldwin-Edwards, Martin (2005), "Migration in the Middle East and Mediterranean», a paper prepared for the Policy Analysis and Research Programme of the Global Commission on International Migration (GCIM).

Barber, Pauline Gardiner y Catherine Bryan (2018), «International Organization for Migration in the field, 'walking the talks of global migration management in Manila», Journal of Ethnic and Migration Studies, 44(10), pp. 1725-1741. DOI: 10.1080/ 1369183X.2017.1354068.

Baum, Joel A. y Tim J. Rowley (2007), "Companion to organizations: an introduction», en Joel A.C. Baum (ed.), The Blackwell companion to organizations, Malden, Mass, Blackwell, pp. 1-34.

Betts, Alexander (ed.) (2011a), Global Migration Governance, Oxford, Oxford University Press. (2011b), «Introduction: global migration governance, en Alexander Betts (ed.), Global Migration Governance, Oxford, Oxford University Press, pp. 1-33.

Bradley, Megan (2020), The international organization for migration. Challenges and complexities of a rising humanitarian actor, London, Routledge.

Brehm, John y Scott Gates (2002), Working, shirking and sabotage. Bureaucratic response to a democratic public, Ann Arbor, The University of Michigan.

Castles, Stephen y Raúl Delgado Wise (eds.) (2008), Migration and Development: Perspectives from the South. International Organization for Migration, Geneva, Organización Internacional para las Migraciones (OIM).

Centro de Información de las Naciones Unidas (UNIC) (s/f), "Managing Migration for the Benefit of All», Tehran, en http://www.unic-ir.org/Factsheets/Factsheet-Eng-IOM.pdf Cohen, Max y Saskia Llewellyn (2019), "The politics of migration data: putting the spotlight on the IOM», Routed. Migration \& Immobility Magazine, en https://es.routedmagazine.com/politics-of-migration-data

De Jong, Sara y Petra Dannecker (2017), «Managing Migration with Stories? The IOM ¿I am a migrant Campaign», Journal für Entwicklungspolitik, 33(1), pp. 75-101. DOI: 10.20446/JEP-2414-3197-33-1-75. 
Deardorff Miller, Sarah (2017), UNHCR as a Surrogate State. Protracted Refugee Situations, New York, Routledge.

Delgado Wise, Raul (2018), «Is there a space for counterhegemonic participation? Civil society in the global governance of migration», Globalizations, 15(6), pp. 746-761. DOI: 10.1080/14747731.2018.1484204.

Dini, Sabine (2018), «Migration management, capacity building and the sovereignty of an African State. International Organization for Migration in Djibouti», Journal of Ethnic and Migration Studies, 44(10), pp. 1691-1705. DOI: 10.1080/1369183X. 2017.1354058. Ellis, David C. (2010), «The organizational turn in international organization theory, Journal of International Organizations Studies, 1(1), pp. 11-28.

Fine, Shoshana (2018), «Liaisons, labelling and laws. International Organization for Migration bordercratic interventions in Turkey", Journal of Ethnic and Migration Studies, 44(10), pp. 1743-1755. DOI: 10.1080/1369183X.2017.1354073.

Gammeltoft-Hansen, Thomas y Ninna Nyberg Sørensen (eds.) (2013), The migration industry and the commercialization of international migration, London/New York, Routledge.

Geiger, Martin (2018), «Ideal partnership or marriage of convenience? Canada's ambivalent relationship with the International Organization for Migration", Journal of Ethnic and Migration Studies, 44(10), pp. 1639-1655. DOI: 10.1080/1369183X.2017. 1354033.

Geiger, Martin y Antoine Pécoud (eds.) (2010), The politics of International Migration Management, London, Palgrave.

Georgi, Fabian (2019), Managing Migration? Eine kritische Geschichte der Internationalen Organisation für Migration (IOM), Berlin, Bertz+Fischer.

Global Commission on International Migration (GCIM) (2005), «Migration in an interconnected world: new directions for action", Report of the Global Commission on International Migration, Geneva.

Hawkins, Darren G., David A. Lake, Daniel L. Nielson y Michael J. Tierny (eds.) (2006), Delegation and agency in international organizations, Cambridge, Cambridge University Press.

Hooghe, Liesbet, Gary Marks, Tobias Lenz, Jeanine Bezuijen, Besir Ceka y Svet Derderyan (2017), Measuring international authority. A Postfunctionalist Theory of Governance, Oxford, Oxford University Press.

Kapur, Devesh (2003), Remittances: The New Development Mantra? Washington DC, The World Bank.

Korneev, Oleg (2018), «Self-legitimation through knowledge production partnerships. International Organization for Migration in Central Asia», Journal of Ethnic and Migration Studies, 44(10), pp. 1673-1690. DOI: 10.1080/1369183X.2017.1354057. 
Lenz, Tobias (2017), "The Rising Authority of International Organisations», GIGA Focus (4), en https://www.giga-hamburg.de/en/publication/the-rising-authority-of -international-organisations

McAuliffe, Marie y Michele Klein Solomon (2017a), «Introduction», en Marie McAuliffe y Michele Klein Solomon (eds.), Migration Research Leaders' Syndicate. Ideas to inform international cooperation on safe, orderly and regular migration, Geneva, OIM, pp. 1-5.

(2017b), Migration Research Leaders' Syndicate. Ideas to inform international cooperation on safe, orderly and regular migration, Geneva, OIM.

Oestreich, Joel E. (ed.) (2012a), International organizations as self-directed actors. A framework for analysis, London, Routledge.

(2012b), «Introduction», en Joel E. Oestreich (ed.), International organizations as self-directed actors. A framework for analysis, London, Routledge, pp. 1-25.

Organización Internacional para las Migraciones (OIM) (2015), «Migration in a world in disarray): IOM director general», en https://www.iom.int/news/migration -world-disarray-iom-director-general

(2017a), «Ensuring Migration Benefits Development», en https://weblog. iom.int/ensuring-migration-benefits-development

158 (2017b), IOM Activities in Support of the Global Compact for Migration, Geneva, OIM. (2017c), IOM vision on the global compact on migration, Geneva, OIM. (2017d), «Second informal thematic consultation for the global compact on migration focused on drivers of migration", en https://www.iom.int/news/ second-informal-thematic-consultation-global-compact-migration-focused-driversmigration

Pécoud, Antoine (2015), Depoliticising Migration. Global Governance and International Migration Narratives, Basingstoke, Palgrave Pivot.

(2018), «What do we know about the International Organization for Migration?", Journal of Ethnic and Migration Studies, 44(10), pp. 1621-1638. DOI: 10.1080/1369183X.2017.1354028.

Piper, Nicola (2017), "Migration and the SDGs», Global Social Policy (40), DOI: 10.1177/1468018117703443.

Piper, Nicola y Stefan Rother (2012), «Let's argue about migration: advancing a right(s) discourse via communicative opportunities», Third World Quarterly, 33(9), pp. 17351750. DOI: 10.1080/01436597.2012.721271.

(2014), «More than remittances: resisting the dominant discourse and policy prescriptions of the global «Migration-Development-Mantra`,Journal für Entwicklungspolitik (JEP), 30(1), pp. 44-66. 
Potaux, Claure (2011), "The current role of the International Organization for Migration in developing and implementing migration and mobility partnerships, en Rahel Kunz, Sandra Lavenex y Marion Panizzon (eds.), Multilavered Migration Governance. The promise of partnership. Milton Park, Abingdon, Oxon, England, New York, Routledge, pp. 183-204.

Proceso de Bali (2018), «About the Bali Process», en https://www.baliprocess.net/

Red de las Naciones Unidas sobre Migración (s/f), «About us», en http://www.migrationnetwork.un.org/sites/default/files/docs/un_Network_on_Migration_TOR.PDF (20 de marzo de 2020), «COVID-19 does not discriminate; nor should our response», en https://migrationnetwork.un.org/statements/covid-19-does-not -discriminate-nor-should-our-response

Rother, Stefan (2010), «The GFMD from Manila to Athens: one step forward, one step back?, Asian and Pacific Migration Journal, 19(1), pp. 157-173.

(2013), "A tale of two tactics: civil society and competing visions of global migration governance from below», en Martin Geiger y Antoine Pécoud (eds.), Disciplining the Transnational Mobility of People, Palgrave Macmillan, pp. 41-62.

(2018), «The ASEAN forum on migrant labour: a space for civil society in migration governance at the regional level?», Asia Pacific Viexpoint, 59(1), pp. 107-118. (2019), «The Global Forum on Migration and Development (GFMD) as a venue of state socialization: a stepping stone for multi-level migration governance?., Journal of Ethnic and Migration Studies, 45(8), pp. 1258-1274. DOI: 10.1080/136918 3X. 2018.1441605. Rother, Stefan y Elias Steinhilper (2019), «Tokens or stakeholders in global migration governance? The role of affected communities and civil society in the global compacts on migration and refugees», International Migration, 57(6), pp. 243-257. DOI: 10.1111/ imig.12646.

Scheel, Stephan y Funda Ustek-Spilda (2019), «The politics of expertise and ignorance in the field of migration management», Environ Plan D, 37(4), pp. 663-681. DOI: 10.1177/ 0263775819843677.

United Nations General Assembly (2016), «New York declaration for refugees and migrants», International Journal of Refugee Law, 28(4), pp. 704-732. DOI: 10.1093/ijrl/eew057

Waltz, Kenneth Neal (2001), Man, the state, and war. A theoretical analysis, New York, Columbia University Press.

Weiss, Thomas G. y Nicholas R. Micinski (2016), International Organization for Migration and the un System: a missed opportunity. Future United Nations Development System. New York.

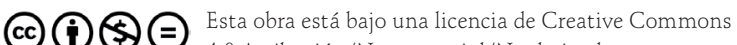
4.0 Atribución/No comercial/No derivadas 